\title{
OBRAS PÚBLICAS Y MODERNIDAD EN QUITO
}

\section{PUBLIG SERVICES AND MODERNITY OF QUITO}

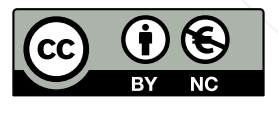

\author{
Inés del Pino Martínez \\ Pontificia Universidad Católica del Ecuador \\ Ecuador
}

Doctora en Arte y Arquitectura por la Universidad Nacional de Colombia, Sede Bogotá (2017). Arquitecta por la Universidad Central del Ecuador (1980). Máster en Estudios de la Cultura, Mención en Comunicación por la Universidad Andina Simón Bolívar (2006). Máster en Gobierno de la Ciudad, Mención en Áreas Históricas por FLACSO-Ecuador (2010). Profesora e investigadora en la Pontificia Universidad Católica del Ecuador. Publicaciones recientes, en libros: Arquitectura Ferroviaria en los Andes de Ecuador. Quito: 2013. En artículos: "El terremoto de Ibarra: 1868". 2018, en América Latina: Espacios urbanos, arquitectónicos y visualidades en transición. 1860-1940, de Alexandra Kennedy Troya (Editor). Universidad de Cuenca, Facultad de Arquitectura y Urbanismo - GAD Municipal del cantón Cuenca. Págs. 93-118. "Permanencias y transformaciones en la plaza de San Francisco de Quito". 2019, en Revista Procesos No. 50 (jul - dic 2019). Quito: Corporación Editora Nacional. Págs. 188-192.

idelpinom@puce.edu.ec orcid.org/0000-0003-4023-2271.

Fecha de recepción: 06 de marzo, 2020. Aceptación: 07 de abril, 2020. 


\section{Resumen}

El presente artículo expone el proceso de modernización de Quito y la transformación de la ciudad, mediante iniciativas del Estado y la empresa privada, entre 1906 y 1960. Una de las acciones fue la ejecución de obras públicas que dan cuenta del interés de los gobiernos por implantar infraestructuras urbanas que preparan a la ciudad al cambio de época. Este proceso fue posible por la aplicación de políticas públicas de salubridad y la provisión de equipamiento urbano como electricidad, agua potable y alcantarillado, además de telecomunicaciones y arquitectura pública moderna, en altura y construida en hormigón armado. Estos fueron algunos recursos que viabilizaron el discurso de la modernidad y el de la arquitectura moderna. En la práctica, representan otra manera de entender la salud, la higiene personal, el confort, la movilidad; es decir, ser moderno. El artículo fue elaborado, sobre todo, a partir de notas de prensa del periódico El Comercio, medio de comunicación que fue un gran aliado del cambio hacia la modernidad.

\section{Palabras clave}

Periódico El Comercio, obras públicas, Quito, ciudad moderna, modernidad, siglo XX.

\section{Abstract}

This article presents the modernization process of Quito and the transformation of the city through initiatives of the State and private companies, between 1906 and 1965. One of the activities was the execution of public works that show the interest of governments to implement urban infrastructures that prepare the city the conditions to stablish modern architecture. This process was possible due to the submission of public health policies and the provision of urban equipment: electricity, drinking water, sewerage, followed by telecommunications and modern public architecture built in reinforced concrete. These were some resources that made the discourse of modernity and that of modern architecture viable. In practice, they represent another way of understanding health, personal hygiene, comfort, mobility, that is, being modern. The article was elaborated mainly from press releases by "El Comercio" newspaper, a means of communication that was the great ally of the change towards modernity.

\section{Keywords}

"El Comercio" newspaper, public works, Quito, modern city, modernity, Twentieth century. 


\section{Introducción}

La implantación de la arquitectura moderna en Quito tomó varios años en incorporar la lógica de este orden en el que manda la razón. En la práctica, la modernidad se estableció cuando la ciudad dispuso de una serie de condiciones suficientes en materia de servicios públicos básicos, como electricidad, alcantarillado y agua potable. Para impulsar el proyecto fue necesario emitir una serie de políticas públicas en la escala nacional y la aplicación de ordenanzas locales que, en la medida de la disponibilidad de recursos económicos, se tradujeron en obras contratadas con empresas europeas o norteamericanas en donde la práctica de construcción industrial tenía a su favor una amplia experiencia. En lo local, esto involucra la aplicación de una tecnología poco o nada conocida, manejada generalmente por ingenieros, y por una mano de obra local con gran capacidad y disposición para aprender las nuevas técnicas de construcción.

La técnica se aplicó con facilidad en terrenos planos. En ese sentido, la expansión de la ciudad se dirigió hacia el antiguo ejido del norte, en donde predominan terrenos con poca pendiente. Era la oportunidad para la creación de nuevos sectores urbanos bajo el concepto moderno. Sin embargo, tanto la ciudad consolidada como la parte de expansión, estaban atravesadas por quebradas que hubo que rellenar y humedales poco aptos para construir; por lo que había que canalizar sus aguas. Por lo tanto, las obras implicaron alguna dificultad para las empresas.

La instalación de agua potable, a cambio del consumo de agua cruda, significó la construcción de tanques de sedimentación y almacenamiento, tratamiento del agua de las vertientes, instalación de bombas y válvulas de regulación del caudal, construcción de zanjas para el tendido de tuberías subterráneas, acometidas a cada una de las casas, colocación de medidores y el cobro de este servicio, entre otros. Todo esto fue un signo de avance tecnológico y progreso; pero, por otra parte, significó la eliminación de un personaje urbano importante durante la colonia, el aguatero.

Esta práctica sugiere el dominio del hombre sobre la naturaleza, que es una de las consignas de la modernidad y del sistema económico capitalista. El relleno se justifica mediante el prejuicio de la autoridad sobre la quebrada, tildándola de espacio insalubre, inseguro y foco infeccioso. Este discurso, que debe ser matizado con las miradas de otros actores, significó, por otra parte, la eliminación de los puentes que formaban parte de la historia de la ciudad. De este modo, Quito dio la espalda a la quebrada; las zonas de humedales se convirtieron en parques públicos.

La instalación del servicio eléctrico fue quizás el de mayor visibilidad y cambio urbano; permitió la circulación del tranvía, iluminó las calles en la noche y, consecuencia de esto, aumentó la sensación de seguridad en el espacio público; favoreció la ampliación del horario de las actividades nocturnas, el paseo urbano y la concurrencia al cine.

Finalmente, los zanjones coloniales para el desalojo de inmundicias ubicados en el centro de algunas calles fueron rellenados para permitir que las aguas negras circulen por el sistema de tuberías de alcantarillado subterráneo. Esto facilitó el paso de vehículos motorizados y la imagen de las calles cambió por la de una superficie continua, lisa, sin olores. Sin embargo, se eliminó una parte de la presencia indígena que realizó la actividad de limpieza de la ciudad, y quedaron únicamente los barrenderos.

Otras obras públicas que merecen atención e influyeron en la imagen de las ciudades fueron el ensanche de calles con parterres arborizados, así como la construcción de hitos o monumentos en donde terminaba la carretera y comenzaba la ciudad. Este punto de inflexión llenó las expectativas del viajero: significaba el fin del viaje y la llegada a la ciudad para decir "ya estamos en Quito"; al tiempo que la imagen de la estación de transporte se convirtió en un referente de orientación y de reconocimiento urbano. 
Desde su creación en 1906, el periódico El Comercio, tuvo como misión informar con independencia y objetividad, estimular ideas de prosperidad, impulsar la agricultura, la industria, el comercio y la cultura; esto explica el nombre del periódico. El mensaje inicial invoca a la libertad de prensa en un momento político de corte liberal. El periódico se convirtió, desde ese momento, en el aliado fiel de la modernidad y el cambio del estilo de vida. A lo largo de sus ediciones promociona el comercio, los bienes raíces y el cine como actividad de entretenimiento, así como de tiempo de encuentro de amigos en espacios de arquitectura moderna, llenos de luz y tecnología.

\section{Las obras públicas}

Las preocupaciones del Municipio por dotar de agua potable, alcantarillado y electricidad están presentes durante todo el siglo. Entre 1906 y 1930, el énfasis es en Quito; y en la década de 1940, se extiende a las parroquias rurales. La dotación de agua está relacionada con la construcción de tanques de captación y tratamiento y la construcción de acometidas a los edificios; pero también tiene que ver con la construcción de lavanderías y baños públicos de agua caliente, sobre todo en los sectores ya consolidados. Las lavanderías públicas reemplazaron al lavado de ropa en los ríos o quebradas que atravesaron la ciudad y en donde existían piedras reservadas por las lavanderas para realizar su trabajo. A partir de la lavandería públi$\mathrm{ca}$, se desprenden otros temas relacionados con la cotidianidad del ordenamiento y la disciplina; el trabajo y la comunicación entre las mujeres de este oficio. Con la aparición de las lavanderías públicas se prohibió el lavado de ropa en las orillas de las quebradas; sin embargo, a pesar de esto, se mantuvo la costumbre de lavar en el río, y se desarrollaron formas de resistencia para evadir la multa.

Con el crecimiento de la ciudad hacia el norte, se obtiene información interesante sobre el lecho de la antigua laguna situada en Iñaquito, sector de La Carolina, en donde confluyen varias quebradas en suelo casi plano. Las noticias promueven, de cierto modo, la capacidad de este espacio para albergar a la ciudad del futuro. El 14 de agosto de 1944, se señala que hay cinco pozos de agua abiertos en este sector; cada uno surte de $63 \mathrm{lt} / \mathrm{seg}$., lo que permite concluir que los cinco proveen de treinta millones de litros al día. Esta cifra garantiza la urbanización de este sector (El Comercio, 1944).

El agua se relaciona también con el relleno de quebradas, el desvío del agua, la construcción de calles sobre el cauce rellenado y la conformación de parques o espacios de uso público. El relleno elimina al puente y permite construir en el norte vías anchas para facilitar el flujo de vehículos. El terreno plano de este sector facilita la movilidad y la construcción de un nuevo tipo de arquitectura. En el centro, el relleno de la quebrada de La Marín fue quizás la solución más acertada para la conexión entre el norte y el sur de la ciudad, sin afectar a la ciudad consolidada. El origen del nombre se conoce mediante una nota del 9 de octubre de 1911, cuando se menciona la cesión de terrenos de propiedad de Luciano Andrade Marín a la municipalidad veinte años atrás, es decir en 1891 (El Comercio, 1911). En 1962, se reconoció el esfuerzo que representa para la municipalidad el relleno de esta quebrada profunda, generalmente realizado con basura a lo largo de 50 años.

Otro relleno importante en la ciudad fue el de la quebrada de Jerusalén, en la parte norte del Panecillo. Esta obra se realizó por etapas; la primera se inició en 1907 y duró dos años, hasta que en agosto de 1909 se inauguró como parte del programa de fiestas del centenario de la Independencia (El Comercio, 1909). La segunda etapa se dio con motivo del centenario de la Batalla del Pichincha, en mayo de 1922. El relleno eliminó varios puentes que existían a lo largo de su recorrido; uno de ellos se encuentra entre la calle Ambato y la Venezuela. Esta obra permitió el paso hacia el pueblo de Chillogallo, en el suroeste de Quito (Del Pino, 2017). 
Sobre el relleno de la quebrada de Jerusalén se construyó la avenida 24 de Mayo, una vía de dos carriles con parterre en la mitad que le dio el carácter de bulevar. Este no progresó, sino que entre 1940 y 1960 se convirtió en mercado popular. Posteriormente, en 1980, se abrió el relleno para construir el viaducto 24 de mayo, una obra compleja que tuvo como objetivo comunicar de manera rápida el este y el oeste de la ciudad. Sobre la losa del viaducto se construyó un nuevo proyecto, al finalizar 1990, que no perduró.

El alcantarillado comenzó en el centro de la ciudad desde los primeros años del siglo y luego se expandió al norte. A manera de ejemplo, el 19 de marzo de 1907 se concluyó la canalización de la calle Flores, cuyas aguas se liberan hacia la quebrada de La Marín (El Comercio, 1907). Por otra parte, el relleno de quebradas forma parte de un discurso político que promete el desarrollo y el progreso; la solución al problema de la basura, alejar al ciudadano del peligro, combatir la enfermedad que se origina en la quebra- da. De este modo, Quito enterró sus quebradas del imaginario y la tradición. Más allá de la función de llevar el agua desde las vertientes del Pichincha y los cerros menores a la ciudad, la quebrada fue un lugar de juego de niños, adolescentes y familias; un espacio para el baño, el lavado de ropa, el paseo y encuentro de parejas: fueron ejes de biodiversidad, de conservación del aire, debido a sus senderos cubiertos de vegetación junto al río o "culuncos". Al mismo tiempo, las quebradas fueron espacios de violencia y muerte; es decir, eran espacios polisémicos, sociales, públicos, de gran significación para la ciudad.

La electricidad y alumbrado público tiene protagonismo en las primeras décadas del siglo XX. Sin este servicio, no habría sido posible el funcionamiento del tranvía, que fue un medio de transporte urbano que circuló entre 1914 y 1947. Tampoco habría sido posible poner en funcionamiento las concreteras para la construcción de edificios en altura y puentes, el funcionamiento del ascensor y la escalera eléctrica.

Figura 1. Plano de Quito de 1914. Publicado por orden de Don Antonio Gil. Escala 1:6.000.

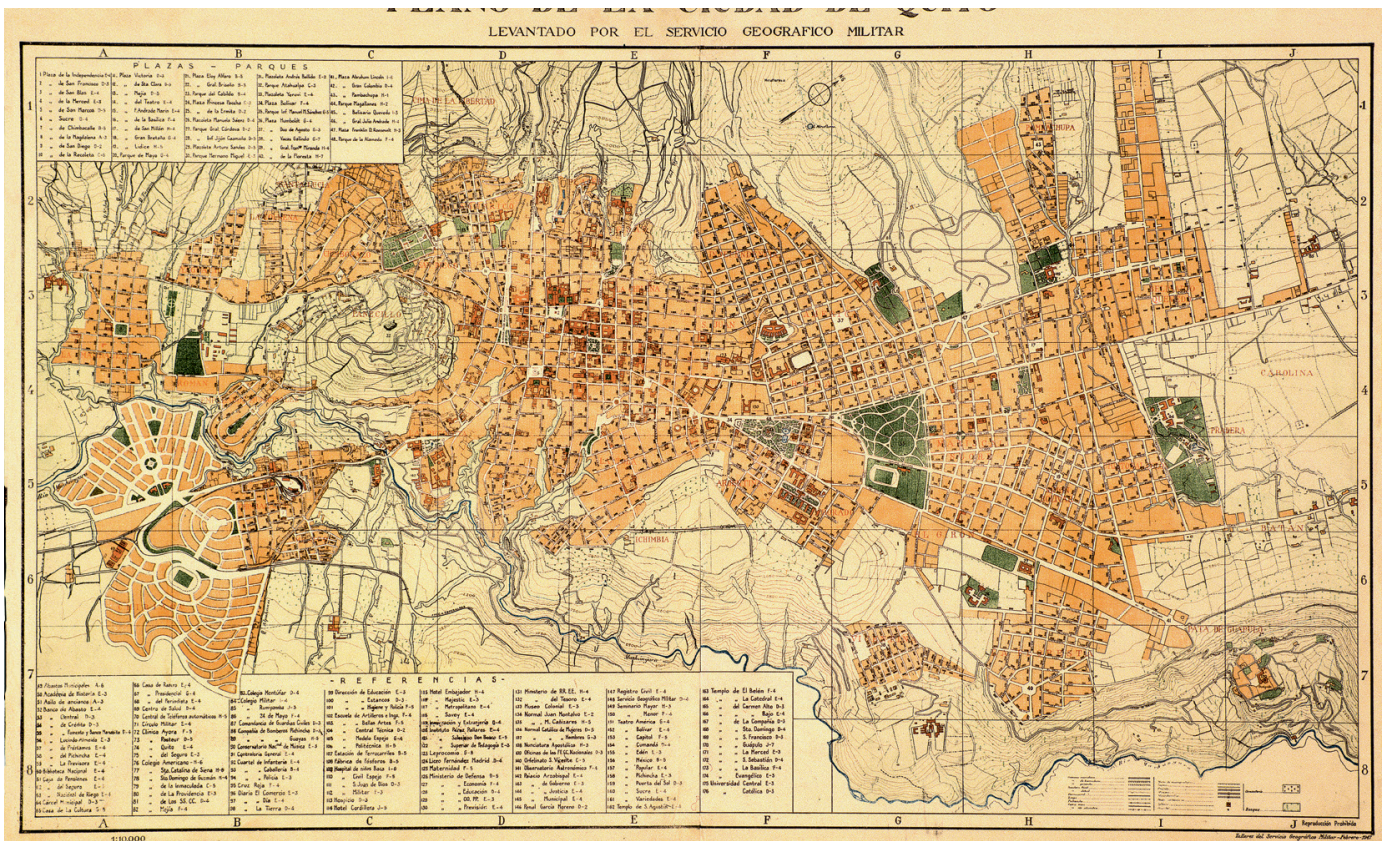

Fuente: H. Hirtz, (s.f.).

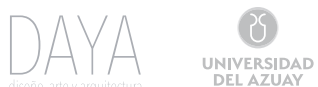


A través de las noticias del periódico, se conocen detalles de la ruta y del funcionamiento del tranvía eléctrico de Quito. Al inicio, todos los pasajeros iban sentados; sin embargo, la demanda creció en poco tiempo y ya en 1920, su capacidad quedó reducida. De esto, se explica la existencia de reclamos por el mal servicio, el público se lamentaba por la congestión en los vagones y las largas esperas en las paradas o estaciones. Un tema poco conocido está relacionado con los accidentes del tranvía y automóviles; por ejemplo, se puede mencionar el atropellamiento de personas, y los suicidios bajo las ruedas del tranvía que llenaron de consternación a la población. El tranvía fue reemplazado por el servicio de los buses en 1947 (Figueroa, 2008).

El suministro de electricidad posibilita la realización de actividades en la noche, ya sea en el espacio público como calles y plazas, 0 al interior de negocios, hoteles, teatros, cines. Con ello, se prolongan las horas de actividad en el espacio público y privado de la ciudad y el entretenimiento, lo cual alimenta la noción de ser moderno y cosmopolita. La luz del alumbrado público da confianza a la población para caminar por la calle y es sinónimo de seguridad.

En otro orden de cosas, durante la primera mitad del siglo, existe una preocupación por diseñar "la entrada a la ciudad". Esta debía ser adoquinada o pavimentada, con doble carril que organice el sentido de la circulación y con un parterre central sembrado de árboles. En el inicio de la carretera se colocaba un hito que podía ser una pirámide 0 un pedestal, con la inscripción del nombre de la ciudad. Vale aclarar que las noticias de comienzos del siglo se refieren al término "pavimentación", que en algunos casos se trata del empedrado de las calzadas.

Cuando Quito comienza a crecer hacia las laderas, entre 1910 y 1950, se encuentra información frecuente sobre la construcción de escalinatas en los barrios de San Juan e Itchimbía;

La construcción de los tanques de agua en El Placer y el ensanche de calles en el barrio de La Tola. Las obras de prolongación, 0 ensanche, dan lugar a disputas entre el ingeniero municipal, quien por lo general era un ingeniero civil, y los pobladores, que ven disminuido su predio por estas obras. Otro dolor de cabeza para este profesional fue el robo del agua, los trámites complejos para las contrataciones, la relación con el gobierno central y la burocracia municipal interna (Luzuriaga, 2013, p. 69).

La década de 1940 trajo una serie de innovaciones en la ciudad. Se hablaba sobre el Plan Regulador de Quito, así como la creación de una oficina para este Plan en la ciudad (El Comercio,1944). La participación de urbanistas uruguayos fue elogiada, no solo por las obras urbanas, sino en trabajos de arquitectura. Los principios teóricos del plan se insertan en la corriente del urbanismo moderno y el CIAM, con ejemplos en todo el mundo.

El estudio del Plan Regulador de Quito (1940 - 1944) tuvo como objetivo ordenar el crecimiento de la ciudad mediante grandes proyectos arquitectónicos que la sectorizan; varios de ellos eran de tipo público como el proyecto del aeropuerto, la inauguración del hipódromo en La Carolina en 1950 (El Comercio, 1950), el proyecto del estadio municipal, la plaza de toros, el campus de la Universidad Central o el centro cívico dan cuenta de la importancia del norte de la ciudad en detrimento del sur.

El Plan Regulador de Quito genera noticia hasta los años sesenta. Una vez iniciado en Quito, tiene impacto en otras ciudades como Cuenca e Ibarra, donde aparecen los nombres de los mismos ingenieros que trabajaron en Quito. Entre ellos se puede nombrar al uruguayo Gilberto Gatto Sobral en Cuenca (Abad, 2009); y el ingeniero José Vásquez Madera en Ibarra (Rocha, 2009).

Por otra parte, el terremoto de Ambato del 5 de agosto de 1949 fue la ocasión perfecta para la elaboración de planes de reconstrucción en las ciudades afectadas, ya sea como una reconstrucción de lo existente o la planificación de ciudades de nueva planta urbana. Para esto, se formó una Junta de Reconstrucción de las ciudades afectadas, liderada por el arquitecto Sixto Durán Ballén. Esta junta trabajó, en particular, en las ciudades de Ambato, Pelileo y Mocha (Moya, 2014; El Comercio, 1949). 
Figura 2. Edificio de la Caja del Seguro Social

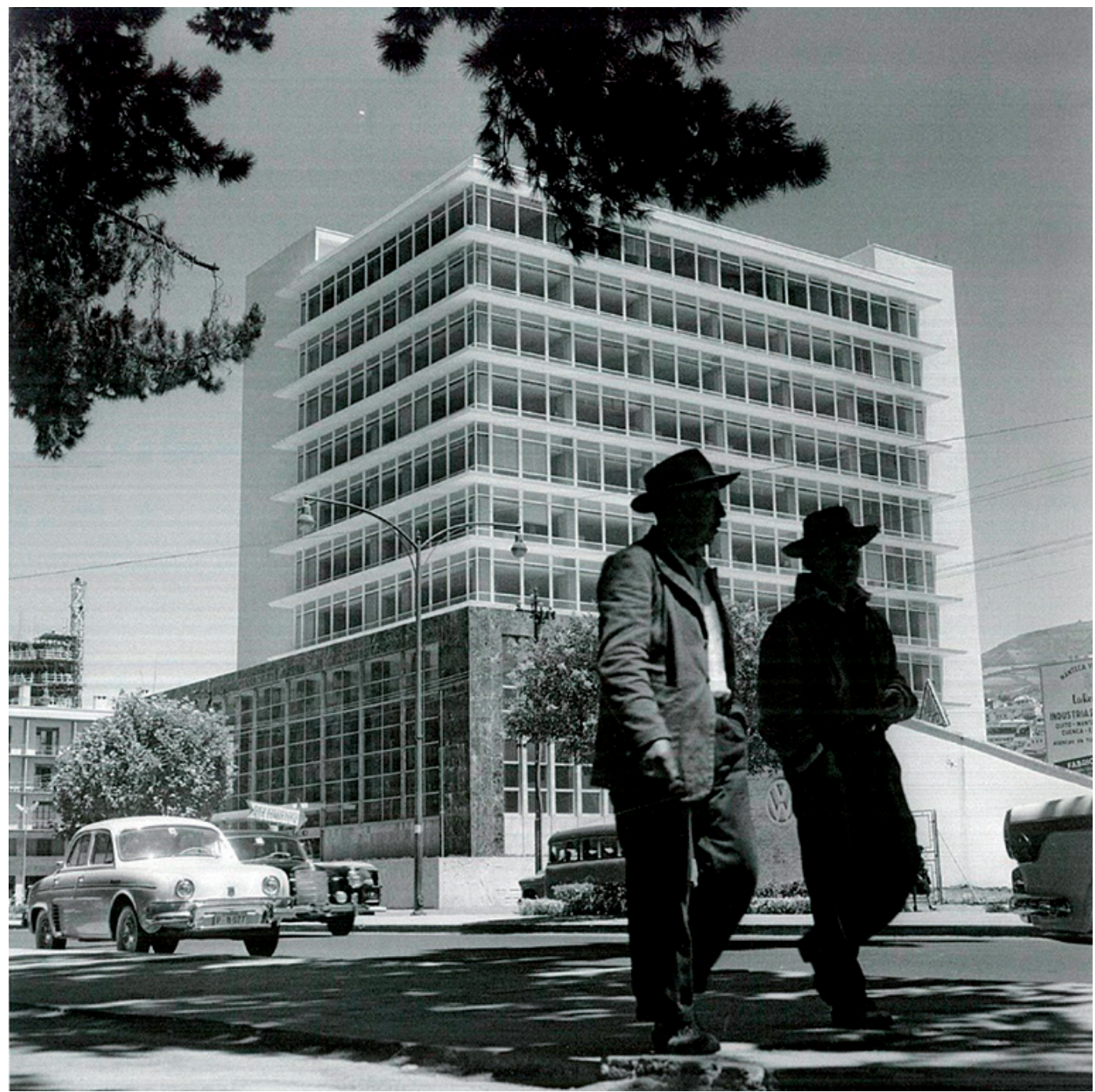

Fuente: Blomberg, (2010).

Sixto Durán Ballén (1921-2016), arquitecto graduado en Columbia University, Estados Unidos, regresó al país en 1947 para trabajar en su profesión. Fue uno de los pioneros de la arquitectura moderna y formó varias empresas constructoras, entre ellas GADUMAG, que diseñó el edificio del Seguro Social, liderada por Durán y un grupo interdisciplinario de arquitectos e ingenieros. Este edificio fue un hito urbano en la década de 1960, estaba ubicado en la avenida 10 de agosto, frente al parque de El Ejido y era un espacio público de entretenimiento popular, con una vista atractiva hacia su entorno. La figura 1 identifica al edificio del Seguro concluido, de arquitectura austera, racional y una ciudad de calles asfaltadas, la sombra de los árboles del parque, autos modernos, y personajes urbanos que se integran y forman parte de esa modernidad local. 
Los empresarios del periódico El Comercio promovieron la arquitectura moderna y las actividades urbanas para hacer de Quito una ciudad cosmopolita. El periódico, junto con Radio Quito, fueron los portavoces del nuevo orden. Algunas empresas vinculadas fueron una cadena de cines y el Teatro Bolívar, inaugurado en 1933. La cadena de cines se amplió en esta década, llegando a trece locales que atrajeron el interés de un público que buscaba un momento de entretenimiento en la ciudad, sobre todo en los fines de semana. Los cines de esta cadena fueron: Alhambra, Variedades, Hollywood, Cumandá, Pichincha, Alameda, Granada, Atahualpa, Puerta del Sol, México, Colón, Capitol y América; ellos se ubicaron en diferentes sectores de la ciudad. Algunos tenían un enfoque específico; por ejemplo, el cine Hollywood proyectaba películas para adultos. El Teatro Bolívar tuvo varios usos: cine, teatro, música, ballet y oratoria. La permanencia de películas en cartelera revela la preferencia del público, y los intereses de la empresa. En la censura de las películas participaron miembros del municipio y la iglesia; es decir, un comité de control del tiempo libre y los gustos en los géneros cinematográficos. La información es abundante y ha sido poco explorada.
A inicios del siglo XX, la noción del tiempo era diferente; hablar de la inmediatez de la noticia y de las primicias era hablar de algo que sucedió hace dos días. Sin embargo, en 1906, ese tiempo era visto como inmediato. Años más tarde, con la radio, los tiempos de llegada de las noticias se acortaron y, con ello, cabría preguntarse si la radio tuvo mayor audiencia que la información escrita. A mediados de siglo, las noticias nacionales e internacionales se publicaban al día siguiente, lo que fue considerado como un tiempo oportuno y un servicio eficaz, aspecto que cambió al finalizar el siglo XX. De este modo, el tiempo acelerado con que viajaban las noticias, formó parte de la noción de modernidad.

Entre 1948 y 1952 se da un periodo en que el país fue visitado por artistas, diplomáticos e intelectuales norteamericanos para dictar conferencias sobre arte y cultura. Ellos manifestaron su admiración por el arte ecuatoriano. Hubo una noticia sobre las ciudades ecuatorianas, el paisaje y los lugares históricos que se considera el inicio de la promoción del país como destino turístico internacional (El Comercio, 1948). Esta idea madurará en los años subsiguientes, con la implantación de otra política pública que incentivó la construcción de hoteles, espacios públicos, carreteras, así como la producción y comercialización de artesanías y la promoción y actividad turística. 
Figura 3. Plano de Quito de 1947. Elaborado por el Servicio Geográfico Militar. Escala: 1:10.000.

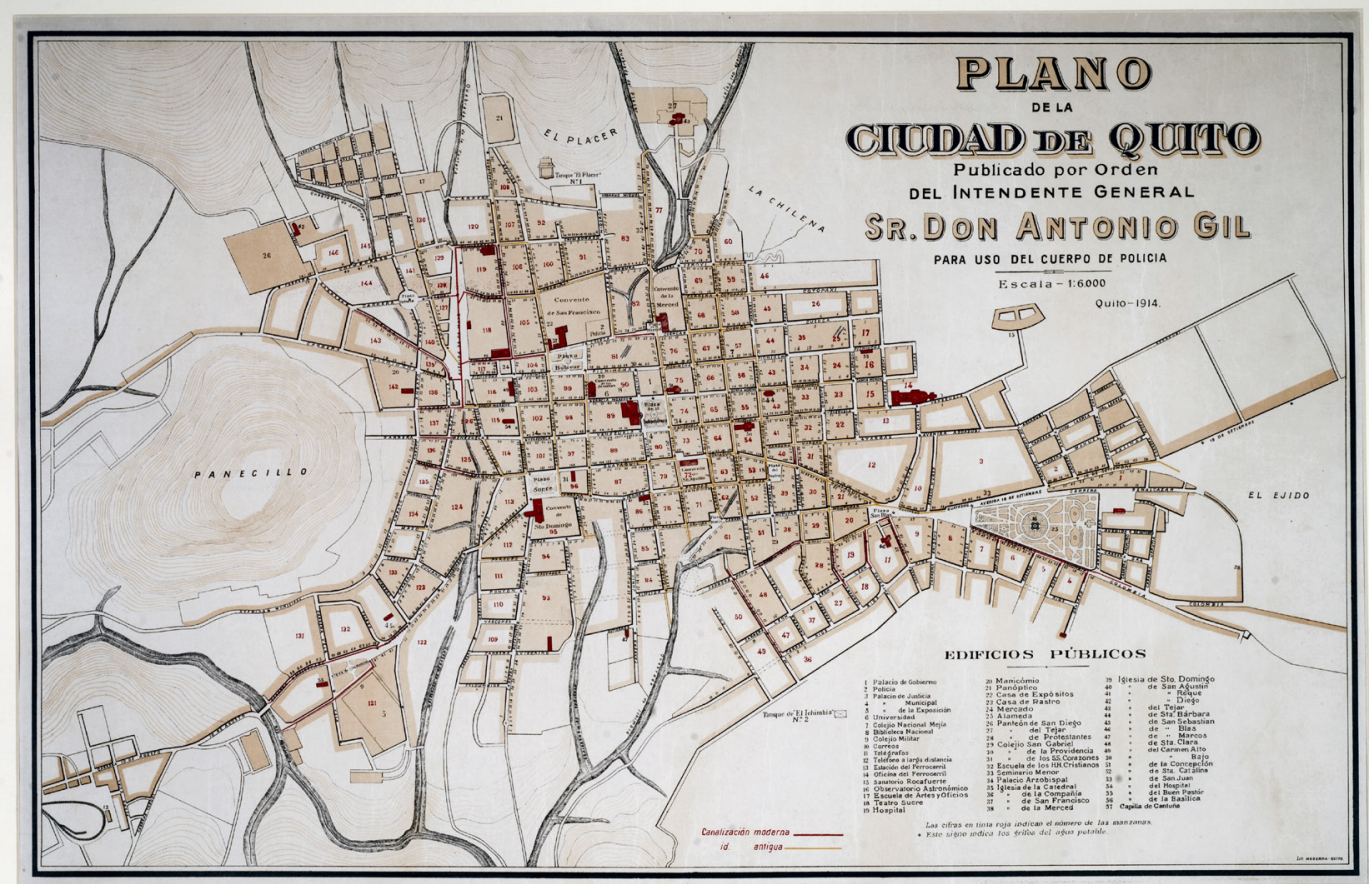

Fuente: H. Hirtz, (s.f.).

Figura 4. Remolcando un Planeador en la Pista del Aeropuerto Mariscal Sucre de Quito

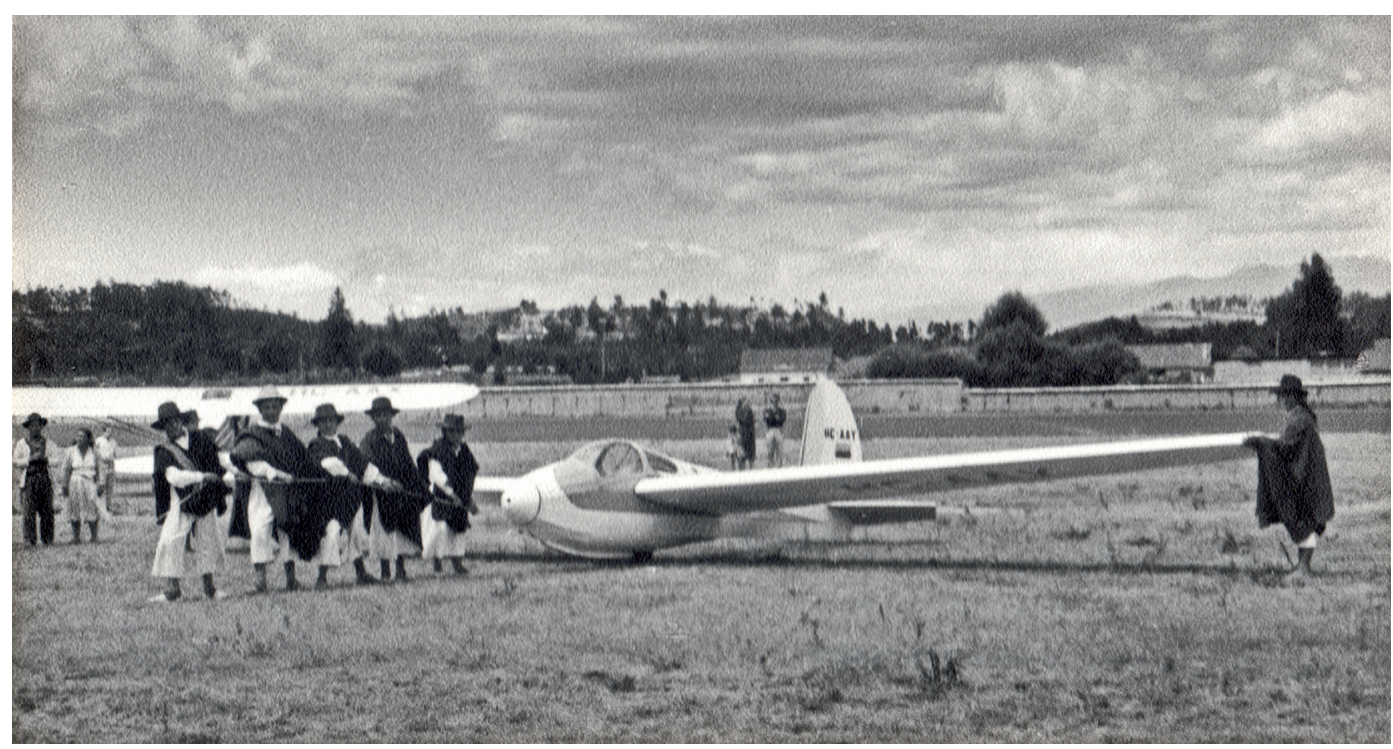

Fuente: G. Hirtz, (1959).

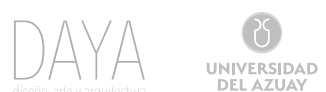


Entre 1940 y 1960, la construcción de aeropuertos y aeródromos hicieron noticia para posicionar a la ciudad como centro que irradia progreso y visión de futuro. Los aeropuertos de Quito y Guayaquil se denominaron "campos de aviación" y los aeropuertos menores, "aeródromos". Los primeros son de mayor tamaño, servicios e importancia; Quito y Guayaquil tienen conexión internacional. Los segundos son pistas para naves más pequeñas para conexiones dentro del país. Esto significó un salto tecnológico importante, no solo por la construcción de las pistas sino por el desarrollo de maquinaria para el movimiento de tierras y la compactación de la pista, equipos para el control de los vuelos y seguridad. Además, esto generaba una conexión de Ecuador con el mundo y consolidaba la noción de Quito como una ciudad moderna, internacional.

El Aeropuerto Internacional de Quito posibilitó la conexión con aeropuertos menores en zonas de difícil acceso por la lluvia, nubosidad y viento. En la Amazonía fueron utilizados para el control de fronteras y la colonización de la región amazónica. Los más importantes fueron construidos de manera simultánea en 1947. Estos fueron el aeródromo de Shell Mera, Macas, y Tena (El Comercio, 1947). En el mismo año, se inauguró otro en la frontera norte, en Tulcán (El Comercio, 1947). El aeródromo de Latacunga, al estar en el centro del país, tuvo también un fin estratégico (El Comercio, 1947). Las ciudades de Manta, Riobamba, Loja, Santa Elena y Ambato también fueron habilitadas para el servicio aéreo, en unos casos con servicio de pasajeros y otros reservados para vuelos militares y de carga. En 1978, la prensa observó que el aeropuerto de Quito estaba en medio de la ciudad y se plantean las primeras ideas para su traslado fuera de la zona urbana, por razones de seguridad (El Comercio, 1978).

Entre 1952 y 1960, las noticias sobre edificios públicos en altura, así como el traslado de edificios educativos y hospitales hacia el norte se vuelve constante. Este es un tema que merece ser desarrollado de manera independiente, por la cantidad de información que proporciona la prensa.
Entre los años 1955 y 1965, la ciudad de Quito se había preparado como destino turístico y sede de eventos internacionales. Uno de ellos fue la XI Conferencia de Cancilleres (1959), que no se realizó por problemas políticos en la región. No obstante, pese a las tensiones en el continente, la V Reunión Panamericana de Geografía tuvo lugar en Quito en ese año.

Hasta la primera década del siglo XX, la plaza fue el punto de partida de la ciudad, y un modelo de estructuración urbana; una manzana sin construir. Sin embargo, en la segunda década del siglo aparecen los planos de barrios y ciudadelas cuyos espacios públicos son nodos de circunvalación de vehículos, como el caso de La Floresta. Se hablaba de manzanas irregulares y alargadas, sin parque o plaza, que se adaptan a la topografía de las laderas. Así también, puede mencionarse a La Colmena que tenía conjuntos de manzanas sin plaza o parque, con desbanques para hacer posible el trazado en cuadrícula.

El 8 de marzo de 1939, El Comercio, anunció que, dentro del Plan de Urbanizaciones de la zona norte de la ciudad, el municipio compró la hacienda La Carolina (El Comercio, 1939). Posteriormente, en este espacio, el Plan Regulador de Quito propuso un centro deportivo; es decir, "un espacio público que combina el parque con espacios de deportes activos" (Ortiz Crespo, 2007, p. 186).

El 3 de diciembre de 1950 se inauguró el Hipódromo La Carolina, y posteriormente, el 1 de septiembre de 1970, el periódico mostraba la nueva imagen del sector con la urbanización La Carolina. El 23 de octubre de 1978 se demuelen las caballerizas del hipódromo para convertir este espacio en parque municipal (El Comercio, 1978). En este año, ya no estaba vigente el Plan Regulador; a pesar de eso, se mantuvo la idea de construir un espacio público para la ciudad. 


\section{Conclusiones}

El seguimiento de la construcción de obras públicas en Quito permite observar la transición de la ciudad, entre la premodernidad y la modernidad; el cambio en su imagen urbana y en el modo de vida de sus habitantes. Este artículo se ha centrado en el periodo comprendido entre 1906 y 1960; sin embargo, los primeros cambios urbanos se produjeron con anterioridad y con obras puntuales en 1800 y en el periodo garciano, a mediados del siglo XIX, con adecuaciones de la Plaza Mayor y en edificios que la rodean, así como el desplazamiento de actividades populares.

La modernidad se estableció hasta 1914 en el centro de la ciudad. Esta llegó con altos y bajos, obras que avanzaban y luego se detenían; obras que tenían el consentimiento colectivo y, al mismo tiempo, la crítica de unos sectores sociales; obras que eran aceptadas con sumisión o resistencia de parte de la población.

La llegada de la modernidad en Quito es progresiva y tiene su ritmo propio. Se crea e interpreta a partir de dos referentes geográficos y políticos: el europeo, hasta aproximadamente 1945, y el norteamericano, que se superpone al primero, y entra con intensidad luego de la Segunda Guerra Mundial, hacia 1949. En este contexto, el cambio no fue radical y el resultado no fue el concebido en las políticas públicas. El resultado fue la interrelación de la tradición con la modernidad. Las preexistencias culturales aparecen en lo cotidiano, matizan lo oficial y producen un resultado diferente; es decir, la presencia de rasgos locales hace la diferencia.

La primera etapa de modernización de Quito inició en el siglo XX y se hicieron realidad mediante la instalación de servicios públicos urbanos que ampliaron su cobertura durante la primera mitad del siglo $X X$, respaldada por el municipio. El cambio tecnológico en el abastecimiento de servicios y apertura de vías en la ciudad marca una diferencia cualitativa en relación con el mismo periodo en el siglo XIX. Una primera prueba de ello es la celebración de los centenarios de la independencia local y nacional que se llevaron a cabo en 1909 y 1922, momentos en que la ciudad contaba con calles anchas, autos, una estación de ferrocarril, monumentos conmemorativos, servicio eléctrico, infraestructura básica, adecuación de calles y plazas y edificios nuevos de instituciones públicas en el centro de la ciudad que habían sido realizados por ingenieros y arquitectos extranjeros, entre otras cosas.

Desde este momento, la energía eléctrica, el alcantarillado, y suministro de agua potable, están considerados como los servicios básicos que determinan la condición de formalidad e informalidad urbana y social. Por una parte, son los indicadores con los que se valora el grado de marginalidad, pobreza y todo lo que pueda estar fuera de la norma y control urbano. Por otra parte, los servicios públicos y el acceso a estos permiten estimar el grado de desarrollo humano, la formalidad y modernidad.

La construcción de la infraestructura urbana y de servicio público forma parte de las historias urbanas de varias ciudades capitales de Latinoamérica, no es específico de Quito. En casi todos los países, las obras fueron contratadas con empresas extranjeras, importando tecnología y diseños que debieron ser adaptados a la necesidad local.

Una segunda etapa de obras públicas se hizo visible cuando los servicios básicos estuvieron establecidos en el centro de la ciudad, y se pretende exhibir una ciudad moderna y cosmopolita, luego de la celebración de los centenarios. Parte de esta imagen son los medios de transporte urbano que dieron ese toque particular a la ciudad. En Quito, el ferrocarril fue el primer medio de transporte que unió la costa y la sierra, impuso su presencia y acumuló el poder de las comunicaciones pues manejó la telefonía y comunicación por cable; la correspondencia y encomiendas; el transporte de carga, desde productos agrícolas e industriales hasta pasajeros y turistas que activaron la economía y la intensidad del movimiento urbano. En lo local, el tranvía fue el primer transporte masivo que conectó el norte y el sur de la ciudad, y contribuyó al crecimiento longitudinal de Quito. Los buses, y más tarde el trolebús, continuaron evidenciando el rostro moderno de Quito. 
Se podría hablar de una tercera etapa, entre 1940 y 1960, cuando el país incorpora la construcción de aeropuertos y arquitectura pública. Es un momento en que arranca la conectividad de Ecuador con el mundo, a través de Quito y Guayaquil; así como la llegada del turismo internacional como un recurso de generación de empleo local y desarrollo del país. Para esto, se apoyaron proyectos de hoteles del Estado, transporte, empresas de turismo, formación de artesanos, adecuación de sitios turísticos. Otros proyectos promovidos por el Estado fueron de vivienda colectiva. Otro aspecto que identifica a este periodo es la presencia de la planificación urbana, con el primer proyecto para la ciudad: el Plan Regulador de Quito, que concibe la ciudad moderna según los lineamientos del CIAM, separando en términos socioespaciales las actividades humanas y dejando atrás la ciudad de composición social heterogénea. No obstante, lo heterogéneo subyace en lo nuevo e internacional.

Del análisis efectuado se desprende que, entre 1900 y 1950, la modernidad se estableció en Quito con el cambio tecnológico en la construcción, la comunicación y el entretenimiento. La tecnología de la construcción incorporó el hormigón armado que se impuso no solo en la arquitectura privada sino también en la construcción de puentes, edificios administrativos y en los programas de vivienda para obreros y empleados públicos.

La población urbana experimentaba con recelo el cambio en el perfil urbano de Quito, donde hasta 1960 el edificio de la Caja del Seguro fue uno de los hitos de referencia y orientación, destacando en medio de las viviendas de pocos pisos.

Según El Comercio, aliado de la modernidad, se deja entrever que las obras iniciadas en Quito se replican luego en las parroquias y provincias. Parecería que existe una política que incentiva la expansión urbana entre 1906 y 1914, mediante un impulso al mercado inmobiliario, tanto en la ciudad consolidada, como en la venta de casas, quintas y haciendas en las parroquias rurales. Por otra parte, y alrededor de 1940, la vida urbana se dinamiza y el periódico contribuye en crear imaginarios del ambiente de la época, a través de las actividades de empresas vinculadas con este medio. Esto es, en la creación de condiciones para el desarrollo de actividades de entretenimiento y la manera de experimentar el tiempo libre; como por ejemplo, escuchar radio en la casa, la fábrica, el campo, la oficina, la ciudad o en el espacio público; así como el asistir al cine, al teatro 0 al restaurante.

\section{Referencias}

Abad, M. T. (2009). Cuenca. En I. Del Pino, Ciudad y arquitectura republicana de Ecuador (págs. 155-227). Quito: PUCE.

Blomberg, R. (2010). Edificio de la Caja del Seguro. Blomberg Quiteño. Archivo Blomberg, Quito.

Del Pino, I. (15 de mayo de 2017). Espacio urbano en la historia de Quito: Territorio, traza y espacios ciudadanos. Obtenido de Universidad Nacional de Colombia: http://bdigital.unal.edu. co/57661/1/TESIS\%20ARTES\%20Ines\%20del\%20Pino\%20210617pq.pdf

El Comercio. (19 de marzo de 1907). Canalización calle Flores. El Comercio, pág. 2.

El Comercio. (23 de febrero de 1909). Terrenos. El Comercio, pág. 2.

El Comercio. (9 de octubre de 1911). Hace 20 años el Doctor Andrade Marín transformó la quebrada en una plazuela. El Comercio.

El Comercio. (8 de marzo de 1939). Plan de urbanismo del norte de la ciudad mediante la compra de la hacienda La Carolina. El Comercio, pág. 1.

El Comercio. (11 de junio de 1944). El Plan Regulador. El Comercio. 
El Comercio. (19 de agosto de 1944). El Plan Regulador tiene oficina. El Comercio.

El Comercio. (14 de agosto de 1944). Pozo profundo La Carolina. El Comercio.

El Comercio. (20 de enero de 1947). Aeródromo de Latacunga. Minga. El Comercio, pág. 1.

El Comercio. (4 de marzo de 1947). Aeródromo de Macas. El Comercio, pág. 1.

El Comercio. (25 de febrero de 1947). aeródromo de Tena. El Comercio, pág. 1.

El Comercio. (10 de julio de 1947). Minga para aeródromo de Tulcán. El Comercio, pág. 2.

El Comercio. (12 de septiembre de 1948). Hermosas ciudades ecuatorianas. El Comercio, pág. 1.

El Comercio. (13 de agosto de 1949). Reconstrucción. El Comercio, pág. 6.

El Comercio. (3 de diciembre de 1950). Inauguración del Hipódromo "La Carolina". El Comercio, pág. 15.

El Comercio. (16 de febrero de 1978). Aeropuerto en medio de la ciudad. El Comercio, pág. 19.

El Comercio. (23 de octubre de 1978). Se demuelen instalaciones del hipódromo para ampliar el parque La Carolina. El Comercio, pág. 50.

Figueroa, J. A. (2008). Sistemas públicos deficitarios en modernidades periféricas. En FONSAL, Camino del hierro (págs. 147-177). Quito: FONSAL.

Luzuriaga, S. (2013). Quito y sus recorridos de agua. Quito: Corporación Editora Nacional-UASB.

Moya, R. P. (2014). Sixto Durán Ballén. Quito: Tramaediciones.

Ortiz Crespo, A. M. (2007). Damero. Quito: Fondo de Salvamento.

Rocha, P. P. (2009). Ibarra. En I. Del Pino, Ciudad y Arquitectura republicana de Ecuador. 1850-1950 (págs. 295-331). Quito: PUCE.

\section{Figuras}

Figura 1. H. Hirtz (s.f). Plano de Quito de 1914. Publicado por orden de Don Antonio Gil. Escala 1:6.000. Obtenido de http://sthv.quito.gob.ec/recursos/historico/mapas-historicos/q1914. jpg

Figura 2. Blomberg, R. (1968). Edificio de la Caja del Seguro Social, hoy IESS. Avenida 10 de Agosto. Quito. Archivo Blomberg.

Figura 3. H. Hirtz (s.f). Plano de Quito de 1947. Elaborado por el Servicio Geográfico Militar. Escala: 1:10.000. Obtenido de http://sthv.quito.gob.ec/recursos/historico/mapas-historicos/ q1914.jpg

Figura 4. Hitz, G. (1962 aprox.). Remolcando un planeador en la pista del aeropuerto Mariscal Sucre de Quito. Quito. Colección Christoph Hirtz. 